\title{
APPLICATION OF A GIS BASED APPROACH TO ASSESS THE ENVIRONMENTAL IMPACTS OF THE MV WAKASHIO OIL SPILL IN THE SOUTH- EAST OF MAURITIUS
}

\author{
Reshma Sunkur \\ School of Sustainable Development and Tourism \\ University of Technology, Mauritius
}

\begin{abstract}
Marine oil spills are regarded as one of the most threatening environmental disasters that can have serious environmental and socio-economic impacts. For islands like Mauritius, such oil spills can have severe repercussions as island communities depend almost entirely on their coastal and marine resources. The MV Wakashio grounded on the coral reef on the south east coast of Mauritius on July 25th 2020, spilling 1000 tons of oil into its clear waters on August 06th 2020. It was the first time the island was faced with such a disaster and in this respect, this study aimed to use a GIS based approach to assess the environmental impacts of the Wakashio oil spill and demonstrate its usefulness in monitoring marine oil spills. SAR imagery was acquired from the Copernicus Platform and ArcGIS was used to process the images. An oil spill map was created using a SAR image dated August 10th 2020. GPS coordinates of the affected sites were recorded and overlaid on a terrain/road network map of Mauritius generated from layers of vector data obtained through the DIVA-GIS portal. The oil spill was mapped on the satellite image using ArcGIS and a vector map of the affected regions was created. From these maps, the short and long term impacts on the environments (marine waters, mangroves, coasts, biodiversity) were examined. This study concludes that GIS is an effective, inexpensive tool that coastal nations around the world, including Mauritius, can use to support management and decision making regarding oil spill preparedness and monitoring as well as disaster management.
\end{abstract}

Keywords - marine oil spill, GIS, Mauritius, disaster management

\section{INTRODUCTION}

Marine pollution is today one of the worst environmental problems that the world is facing along with climate change and deforestation [1]. As the demand for fossil fuels increases,

\author{
Chandradeo Bokhoree \\ School of Sustainable Development and Tourism \\ University of Technology, Mauritius
}

so does the risk of oil spills during overseas oil transportation [2] which can then have serious environmental and economic impacts [3]. When an oil spill occurs at sea, currents, waves and tide action disperse oil particles which then make their way towards the coast. As it currently stands, globally, coastal regions account for only $2 \%$ of the total land area, yet, approximately $10 \%$ of the global population lives within the $10 \mathrm{~m}$ elevation of sea level [4]. As the oil washes ashore, it is very difficult to clean up and restore the impacted ecosystems [5]. What's more, crude oil leaks, whether accidental or intentional, can be quite catastrophic when the geographic context is itself sensitive such as semi-enclosed basins like the Baltic Seas [2]. Therefore, maritime authorities must plan strategically and prepare the necessary response scenarios to possible oil spill accidents [2]

When it comes to the Small Islands Developing States (SIDS), [6] declare that their specific characteristics and reliance on existing traditional knowledge make it difficult for them to cope with challenging environmental conditions. To date, there have been no major oil spills in the SIDS though most of them have an Oil Spill Contingency Plan in place to prepare for such events. When oil spills occur in the sea of the SIDS, which are far larger in terms of territorial waters compared to land area, the consequences are quite catastrophic. As reported by the [7], most of the settlements, infrastructure and agricultural lands are located on the coasts in the SIDS. The livelihoods of the communities are also based on the coastal and marine environments from fishing, tourism to local entertainment. What's more, they also contain the world's richest marine biodiversity like coral reefs, seagrass meadows, mangroves and wetlands. Marine oil spills thus heavily affect their marine biodiversity and cripple their economic powers. 


\section{International Journal of Engineering Applied Sciences and Technology, 2021 \\ Vol. 6, Issue 4, ISSN No. 2455-2143, Pages 10-19 \\ Published Online August 2021 in IJEAST (http://www.ijeast.com)}

As for Mauritius, it is located in one of the busiest shipping lanes in the world in the Indian Ocean with Port Louis being the most connected port in Eastern Africa. More than 2000 ships cross the EEZ of Mauritius each month, sailing by some 12 nautical miles off the coast [8] but only two incidents at sea were recorded [9]. The first one occurred in 2005 when the MSC Katie and the MV Nordsun collided in the port off Port Louis. The MSC Katie sustained cracks but the authorities managed to ground it on nearby reef to avoid an oil spill into the sea. The second incident occurred in 2016 when the MV Benita ran aground coral reef in the south east of Mauritius and was damaged; a salvage company was quick on site and oil was immediately pumped from the vessel to prevent a catastrophic spill in the sensitive marine region [9]. To date, the Wakashio Oil spill that occurred in the south eastern region of Mauritius is one of the worst socio-ecological problems that ever hit the nation. The MV Wakashio grounded on the coral reef at Pointe d'Esny on July 25th 2020 and leaked approximately 1000 tons of oil into the coastal waters on August 06th 2020. Currently, no oil spill management and/nor monitoring assessment study has been carried out in Mauritius. In this respect, this study aimed to use a GIS based approach to assess the environmental impacts of the Wakashio oil spill in the south eastern region of Mauritius and demonstrate its usefulness in monitoring marine oil spills. As Mauritius is a signatory to both the Sendai Framework for Disaster Risk Reduction and the Sustainable Development Goals, with SDG 14 specifically calling for the conservation and sustainable use of the oceans, seas and marine resources, this study aimed to further coastal and marine oil spill monitoring studies using GIS as an inexpensive technological tool that provides high quality data and allows accurate predictions to be made.

\section{MATERIALS AND METHODS}

\subsection{Study Area}

The Republic of Mauritius includes the mainland island Mauritius and outlying islands Rodrigues, Agalega, Tromelin, Cargados Carajos and the Chagos Archipelago and is located in the Indian Ocean. The total land area covers over $2,040 \mathrm{~km}^{2}$ and the EEZ is approximately 2.3 million $\mathrm{km}^{2}$ in size with an additional $396,000 \mathrm{~km}^{2}$ jointly managed with Seychelles. Mauritius has an estimated population of 1.27 million people and the GDP is mainly based on manufacturing (13.1\%), financial services $(11.7 \%)$, construction and real estate $(10.5 \%)$, tourism $(8.6 \%)$, logistics $(6.4 \%)$ and ICT $(5.7 \%)$. Mauritius has a sub-tropical climate which is mainly influenced by the southeast trade winds with winters spanning from June to October and summers from November to March. The south-easterly trade wind is the main wind field of Mauritius stemming from the semi-permanent anticyclone of the Indian Ocean which also exhibits remarkable irregularity from June to August. The major wave generating systems which cause large wave conditions are a result of the passage of cold fronts together with their low-pressure systems that move eastward from main continental Africa. The study area directly faces the southeast trade winds and rough swells due to anti-cyclonic weather conditions. The MV Wakashio wrecked on the coral reef at Pointe D'Esny with coordinates $20^{\circ} 26^{\prime} 17.23^{\prime \prime} \mathrm{S}$ and $57^{\circ} 44^{\prime} 40.67^{\prime \prime} \mathrm{E}$ as shown in Fig. 1.

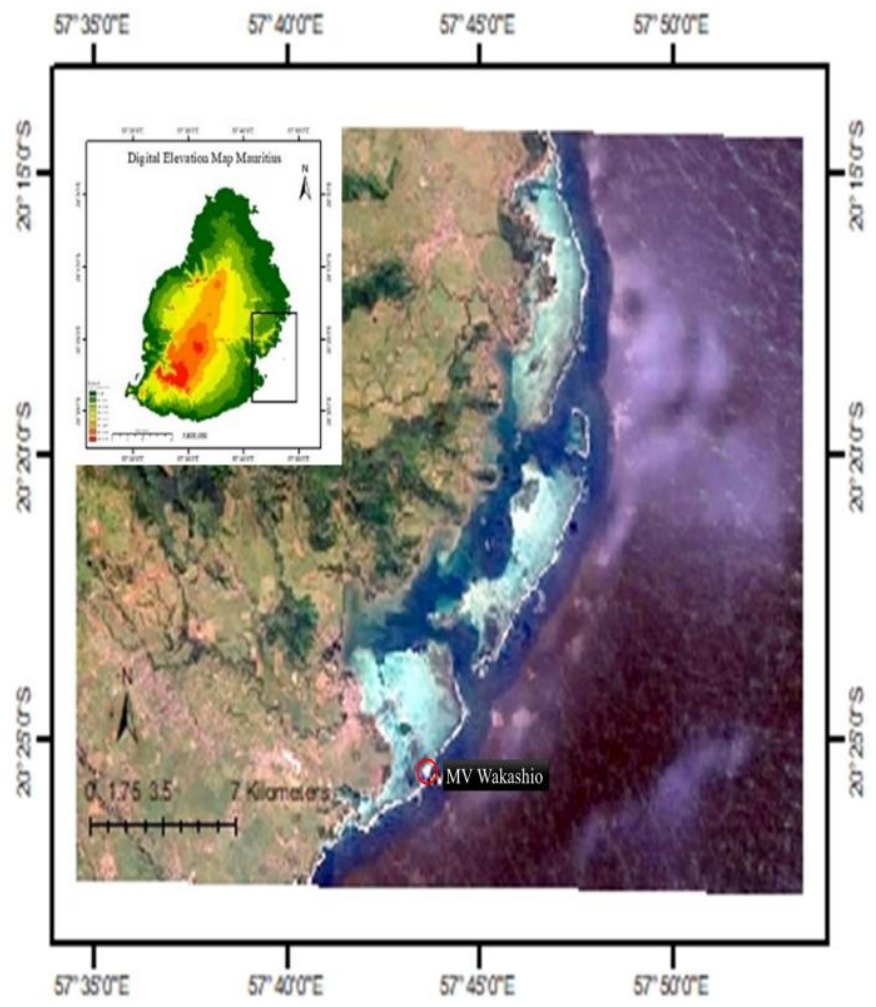

Fig. 1: Study area from satellite image of Mauritius obtained from Google Earth Pro and position of the MV Wakashio wreck on the south east region of Mauritius

\subsection{Wakashio Oil Spill}

The MV Wakashio crashed on the barrier reef at Pointe d'Esny, on the south-east coast of Mauritius on July $25^{\text {th }} 2020$ on its way to Tubarao, Brazil. The vessel was registered in Panama but it belonged to the Japanese Okiyo Maritime Corporation, an associate of the Nagashiki Shipping Company Ltd and was chartered by the Mistsui O.S.K. The vessel was not carrying any cargo but it contained 3,894 tons of fuel, 207 tons of diesel and 90 tons of lubricants (UN, 2020). The Mauritian government activated its National Oil Spill Contingency Plan deploying oil booms around the wreck but due to harsh weather conditions, the vessel could not be tugged. Smit salvage was assigned to keep the vessel afloat by July $28^{\text {th }} 2020$ and to pump the more than 4,000 tons of oil on 


\section{International Journal of Engineering Applied Sciences and Technology, 2021 \\ Vol. 6, Issue 4, ISSN No. 2455-2143, Pages 10-19 \\ Published Online August 2021 in IJEAST (http://www.ijeast.com)}

board. Rough sea conditions once more haltered the pumping process and oil started to spill into the sea from a breached tank at a high rate on the $6^{\text {th }}$ of August 2020. By August $10^{\text {th }}$ 2020, 1000 tons of oil had spilled into the clear waters of Pointe D'esny and hit the coast, drifted near the island nature reserve of Ile aux Aigrettes and loomed near the RAMSAR site, the Blue Bay Marine Park.

\subsection{Satellite imagery extraction}

Satellite images where the oil spilled were collected from the Copernicus Open Access Hub (https://scihub.copernicus.eu/) from the European Space Agency (ESA) database. The oil pollution records were searched from August $6^{\text {th }} 2020$ to August $11^{\text {th }}$ 2020. Satellites that are used for the Sentinel-1 mission are equipped with a SAR system that operates at a Cband. The ground range coverage of the SAR sensor is around $250 \mathrm{~km}$ with pixel spacing equal to $10 \mathrm{~m} \times 10 \mathrm{~m}$. This thus shows that the SAR sensors can capture wide areas of interest including small objects like ships [10]. In this case, the SAR images were collected with VW band (vertical polarization transmitted - vertical polarization received) and some preprocessing steps were undertaken. As the Sentinel Application Platform (SNAP) was unavailable at the moment the study was ongoing, the images were processed using ArcGIS. The oil spill was located in the south-east of Mauritius and the region of interest was cropped and re-scaled as suitable. A speckle filter was used to suppress the sensor noise scattered in the image. As speckle noise has a granular texture, a $7 \times 7$ median filter was used to suppress it. A linear transformation was applied for $\mathrm{dB}$ to real luminosity values conversion. The extent of the oil spill on the resulting image was visually assessed with ground truth and the main data including the land, sea surface, oil spills, look-alikes and the MV Wakashio was retained. Excluding look-alikes with ground truth, the oil spill was mapped using the polygon feature of ArcGIS. The polygon was then overlaid on a satellite image of a cropped section of Mauritius downloaded from Google Earth Pro so as to make the final oil spill map more lucid.

\subsection{Assessing the impacts of the oil spill on the environment} As of August $11^{\text {th }} 2020,18$ sites had been affected by the oil spill and were off limit to the public for clean-up. The sites were visited on December $10^{\text {th }} 2020$, their GPS coordinates were recorded using Google Maps and the existing environments and biodiversity were surveyed. Shapefiles for Mauritius's terrain and road network (only datasets publicly available) were downloaded from the Diva-GIS Portal (https://www.diva-gis.org/) and overlaid to create a map of the affected site on ArcGIS. The map was georeferenced to the UTM 40S projection system and cropped to the southeast extent of Mauritius only. Based on the extent of the oil spill on the map, the environmental impacts were assessed.

\section{RESULTS}

\subsection{Satellite Image Processing}

Following the above-mentioned steps, the final processed images were obtained as shown in Fig. 2-5. Fig. 2 shows the SAR processed image showing the extent of the oil spill as black plumes. The oil spill, counter-checked with ground truths, was mapped in yellow to show the extent of the spill as of August $10^{\text {th }} 2020$. From the image, it is visible that the oil slick moved south towards the Blue Bay Marine Park and Pointe Vacoas and north up to Trou d'eau Douce. As the sea conditions were rough since the wreck occurred, the southeast trade winds pushed the oil covered water towards the shore, crashing on beaches, estuaries and mangrove swamps. This can be clearly seen in Fig. 5 where the oil spill was overlaid on a satellite image of the southeast coast of Mauritius.

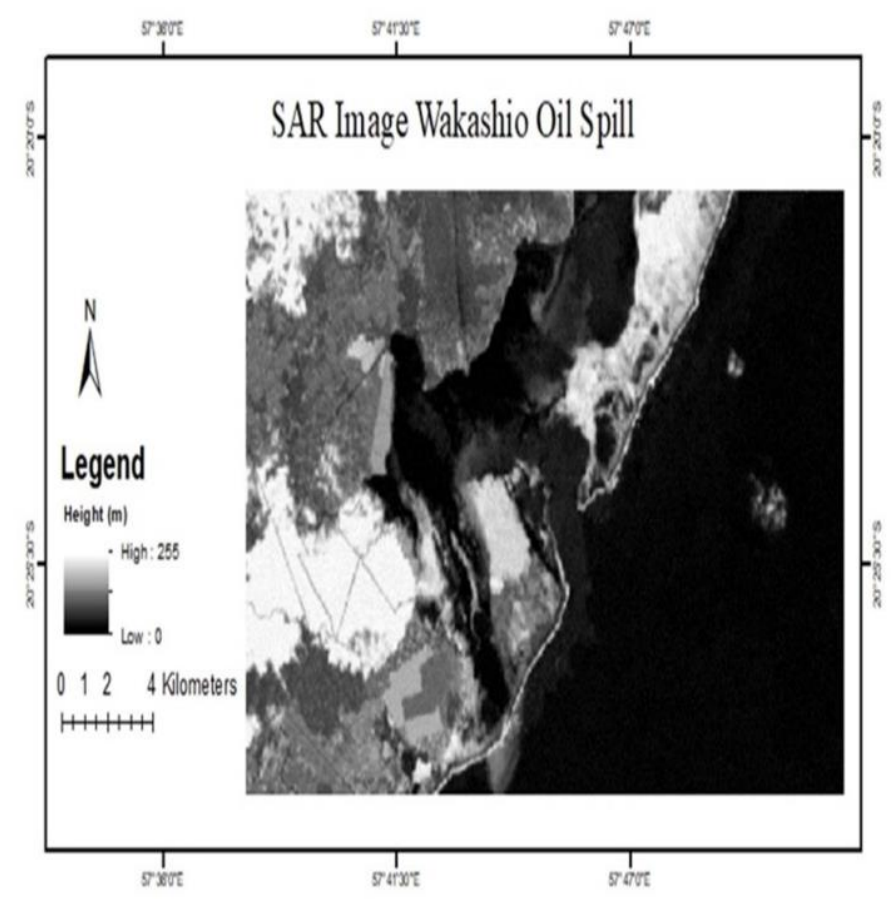

Fig. 2: SAR Image of the Wakashio oil spill 
International Journal of Engineering Applied Sciences and Technology, 2021

Vol. 6, Issue 4, ISSN No. 2455-2143, Pages 10-19

Published Online August 2021 in IJEAST (http://www.ijeast.com)

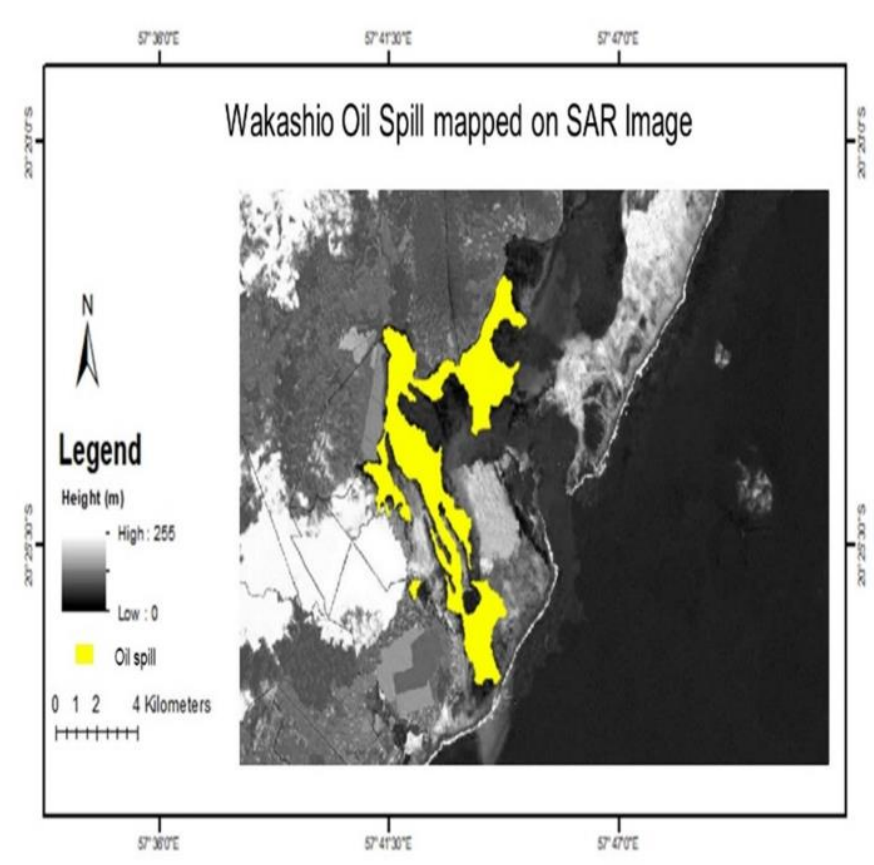

Fig. 3: Wakashio oil spill mapped in yellow on SAR image

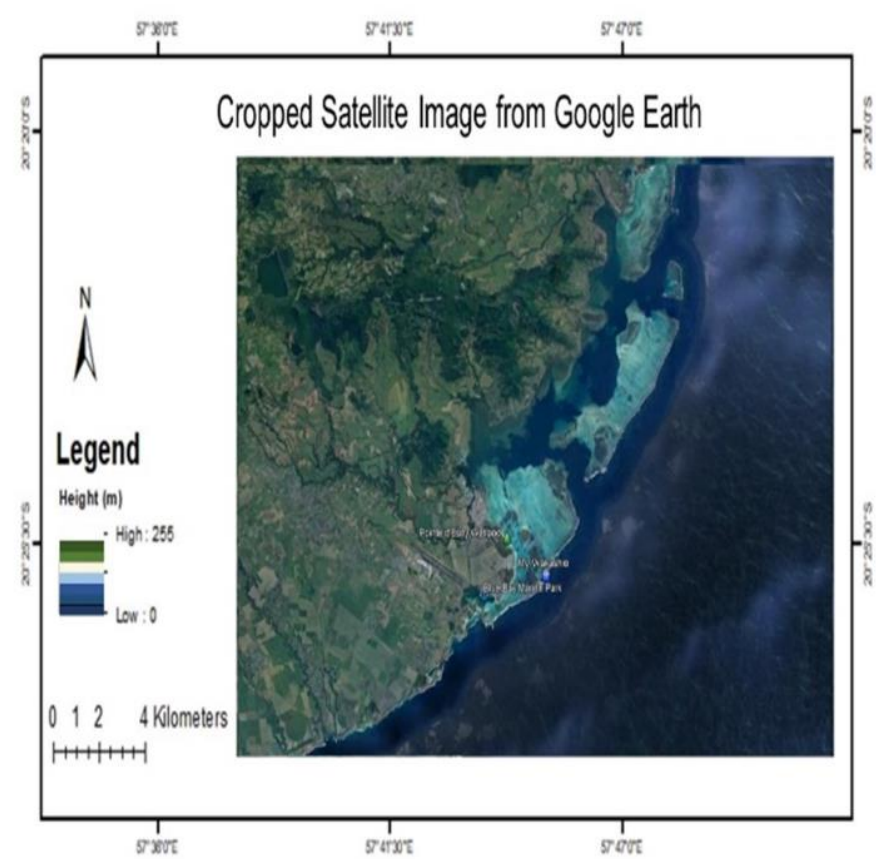

Fig.4: Cropped satellite image of the south east region of Mauritius from Google Earth

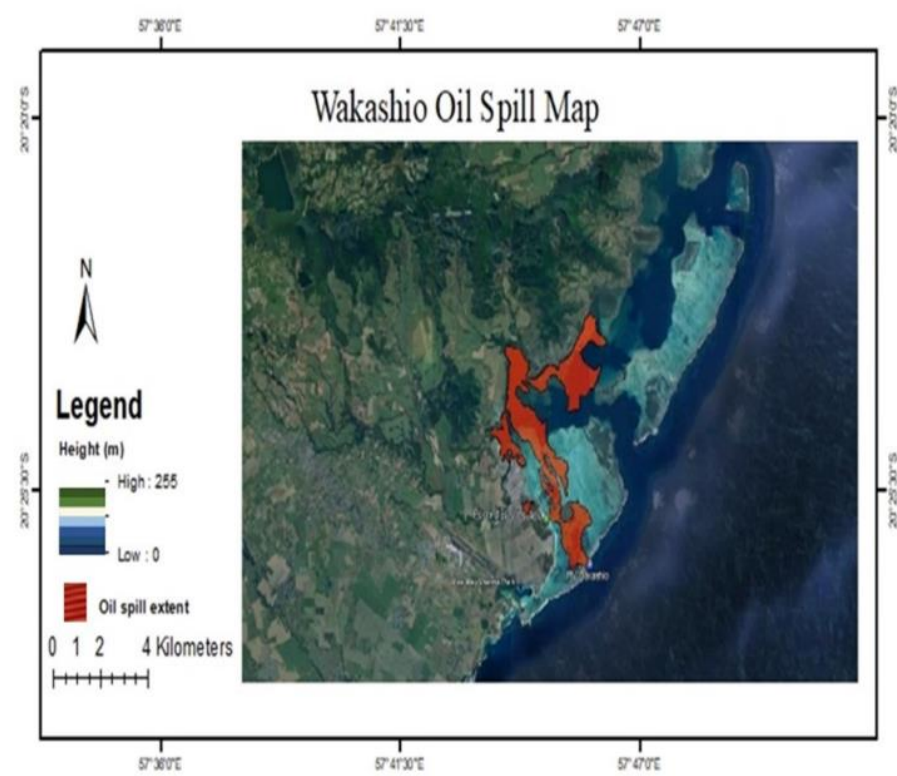

Fig. 5: Oil spill map on Google satellite image with oil spill extent as of 10 August 2020

3.2. Mapping affected sites on ArcGIS

The impacted sites as of August $11^{\text {th }} 2020$ include Bois des Amourettes, Pointe d'Esny, Pointe Vacoas, Pointe Jerome, Blue Bay Marine Park, Pointe Brocus, Falaise Rouge to Mahebourg Waterfront, Riviere des Creoles, Anse Jonchée, Bambous Virieux, Pointe du diable, Grand Sable, Pointe aux Feuilles, Quatre Soeurs, Deux freres, Grand River South East, Ile aux Cerfs, Ilot Mangenie and Trou d'eau Douce [11]. These sites were visited on December $10^{\text {th }} 2020$ as ground truth and the GPS coordinates were recorded into ArcGIS to create an overlap map with terrain and road network. 


\section{International Journal of Engineering Applied Sciences and Technology, 2021 \\ Vol. 6, Issue 4, ISSN No. 2455-2143, Pages 10-19 \\ Published Online August 2021 in IJEAST (http://www.ijeast.com)}

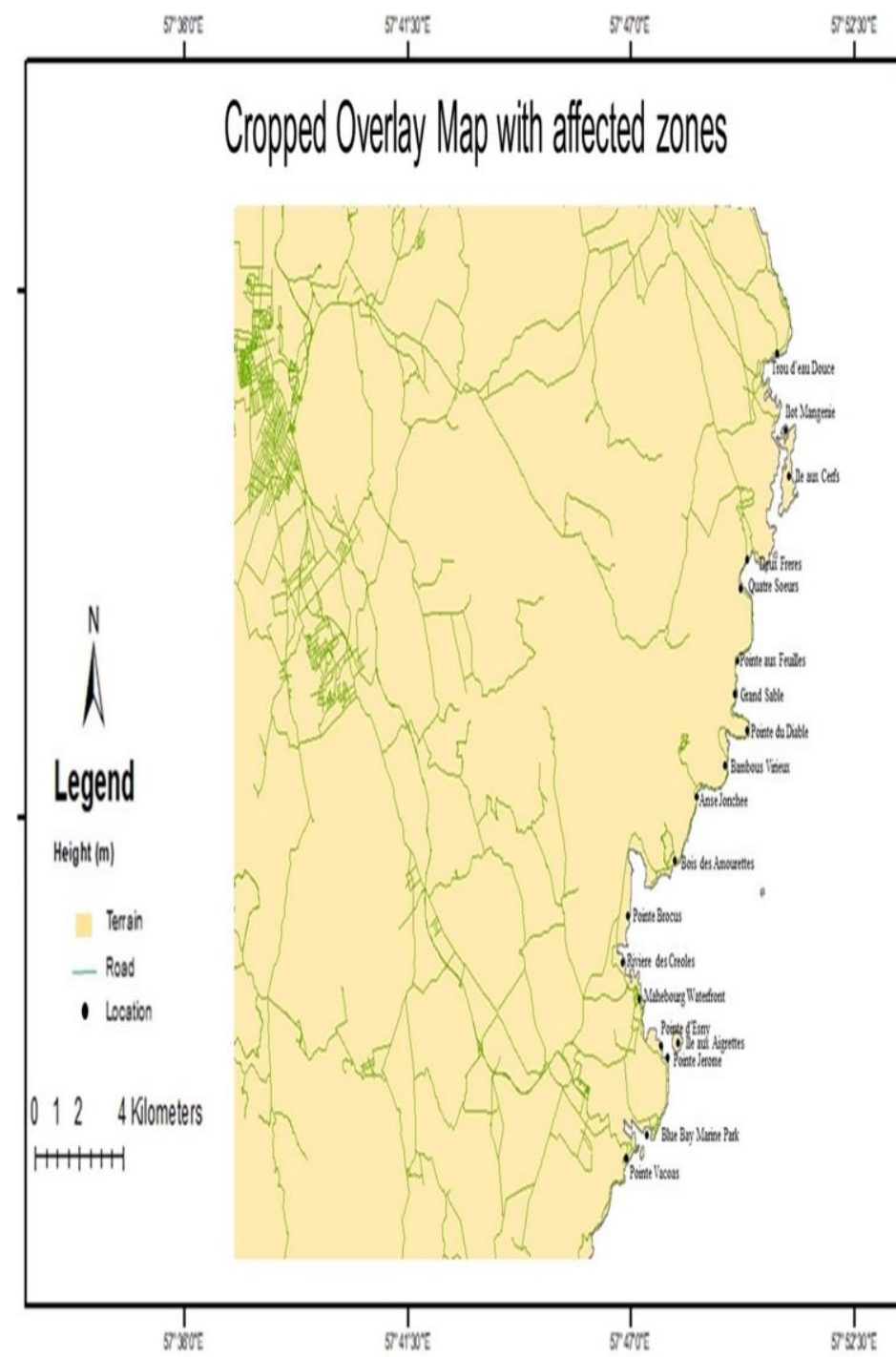

Fig. 6: Site map of Wakashio oil spill and affected regions constructed on ArcGIS as of August $11^{\text {th }} 2020$

\subsection{Inventory of biodiversity found on the south east coast}

The MV Wakashio stuck to the barrier reef in the south eastern region of Mauritius. This part of the island harbors many environmentally sensitive regions including wetlands, beaches, intertidal regions, salt marshes, estuaries and islets which in turn support mangrove forests and strands, coral reefs and seagrass beds. Though Mauritius is mainly surrounded by fringing reef, barrier reefs typically grow on the coast of Mahebourg extending from Ile de la Passe to $\sim 9 \mathrm{~km}$ northwards. Fringing reefs grow in their inner layers over a distance of $1.5 \mathrm{~km}$ laterally along the shore. A $2 \mathrm{~km}$ wide by $20 \mathrm{~km}$ deep canal separates the inner reef from the rest of the mound [12]. Two internationally RAMSAR protected sites are located there namely the Pointe D'esny Wetland and the Blue Bay Marine Park. The Pointe D'Esny Wetland is a 22 ha mangrove forest, the largest and oldest of Mauritius where the two mangrove species of Mauritius Brugeira gymnorrhiza and Rhizophora mucronata grow as well as the endangered plant Zornia vaughaniana. To date, there has been no inventory of the existing fauna in the mangroves of Mauritius but generally, crabs, birds, stray dogs and cats and a plethora of insects can be seen in the mangroves on the southeast coast. The Blue Bay Marine Park is a 353 ha marine conservation stretch where the patch reef ranks amongst the best in the world and is the only place in Mauritius where the stony coral Montipora aequituberculata grows. Inventory of the biodiversity of the park shows that there are 108 coral species, 233 fish species, 201 mollusc species, 1 turtle species, 31 algae species and the two mangrove species that grow along the coast [13]. A number of offshore islet reserves and parks are also located on that coast including the most famous islet reserve in the Mascarenes, Ile aux Aigrettes, located just off the north of the ship wreck which is home to $20 \%$ of the indigenous Pink Pigeon population and remnants of the original coastal forest of Mauritius. There is also Ilot Fouquets which is an important site for nesting birds, Ilot Vacoas found in the Mahebourg bay where native reptiles like Bouton's skink, Bojer's sking and Nactus gecko live and shearwaters nest, the sandbacks Ilot Flamants and Ilot Oiseaux, Ilot Fous where Lesser Noddies roost and the shoreline purslane (Sesuvium ayresii) grow, Ilot Mariannes where shearwaters nest and the native green-backed Heron and Whimbrel fly around as well as 29 species of vascular plant species grow including the Veloutier blanc (Argusia argentea) and the Bois matelot. Ilot cerfs which is of commercial importance for tourists and locals is found adjacent to Trou D'eau Douce. The two sea turtle species that are often sighted in Mauritius, namely the green turtle (Chelonia mydas) and the hawksbill turtle (Eretmochelys imbricate) also swim in that region [14]. As for cetaceans, spinner dolphins have been sighted on that part of the coast, as well as the Indo-Pacific bottlenose dolphins and humpback whales [15]. Seagrass beds are also found in the shallow waters and the estuaries of Riviere des Creoles and Grand River South East where a number of fish species forage plus seahorses. To date, there is limited information on the marine and coastal biodiversity found on the south east coast of Mauritius while assessing the environmental impacts of the Wakashio oil spill on individual species is beyond the scope of this study.

\section{Discussion}

\subsection{Using GIS to monitor oil spills}

Detecting oil spills and warning the concerned authorities as soon as possible is crucial to mitigate the ecological disasters that these can become, control the oil spill and ensure that humans lives are not at risk [10]. [16] contend that since the catastrophic oil spill from the Deepwater Horizon, a plethora of research has been devoted to understand the impacts of oil spills at sea. These efforts, combined with short-term and 


\section{International Journal of Engineering Applied Sciences and Technology, 2021 Vol. 6, Issue 4, ISSN No. 2455-2143, Pages 10-19 \\ Published Online August 2021 in IJEAST (http://www.ijeast.com)}

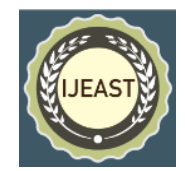

long-term observations, have produced an array of computational tools and analytical frameworks to explore the potential impacts of oil spills in time and space [16]. It includes the development of oil spill risk and impact modeling suites and decision support systems (DSS) designed to increase the efficiency of response and to mitigate risks. In particular, it is the use of remote sensing, GIS, computational modeling, mathematical programming and spatial statistical methods that is fueling the backbone of oil spill research at sea [16]. More recently, the incorporation of Unmanned Aerial Vehicles (UAVs) and Autonomous Surface Vehicles (ASVs) for assessing and monitoring oil spills at sea is becoming increasingly popular. [16] contend that while UAVS and ASVs technologies are currently in their infancy, they will eventually be key tools to reduce the costs associated with marine oil spill monitoring, provide more detailed characterizations of oil slicks and reduce the uncertainly associated with oil spill impact assessment.

As for Mauritius, there has been no published research on marine oil spill detection and monitoring to date. The National Oil Spill Contingency Plan drafted in 1990 was deemed suitable when the Wakashio grounded on the coral reef at Pointe D'Esny on July $25^{\text {th }} 2020$ and was activated on July $26^{\text {th }} 2020$. But oil spilled at a high rate into the sea on August $6^{\text {th }} 2020$ and in this respect, the Minister of Fisheries declared that it was the first time that the island was facing such a catastrophe and was insufficiently equipped to handle it [17] while the Prime Minister stated that the National Oil Contingency Plan would be updated [18]. As [19] point out, oil spills can be very difficult to manage as by the time responders arrive at the scene, the slick has moved, dispersed, dissolved or sunk. This study confirms that indeed GIS coupled to satellite imagery is an effective means to monitor oil spills, predict oil slick movement and assess subsequent effects. It is an excellent tool to help first responders, decision makers and environmental experts to tackle the disaster. With the appropriate information such as wind, wave and current, trajectory modeling of an oil spill can be generated using GIS thus making disaster response and recovery more effective. GIS has proven to be an excellent tool to assess resources, oil spill response and planning and damage assessment as it contributes significantly to the correct interpretation of oil slicks visible on SAR images [20]. It includes the integration of geographical and infrastructure data plus oil slick signatures that help in oil spill mapping. By compiling data from other sources such as ground truths, geodatabases and remote sensing data, GIS permits the retrieval of valuable information like predicting oil slick movement, revealing onshore/offshore sources, estimating the intensity of oil pollution and assessing consequent impacts. It also provides a user-friendly and dynamic interface to explore various attributes and physical information during an oil spill. By overlaying these parameters on geographical layers, useful information can be obtained such as logistics routes, booming plans, waste sites, sensitive areas mapping as well as pre-defined Net Environmental and Economic Benefit Analyses. Moreover, GIS can improve the efficiency of oil spill contingency planning as risks can be predetermined and consequently strategies can be developed to mitigate the impacts of oil spills. [21] declare that GIS based oil spill maps coupled to ground truth data can be considered as one of the most important elements to manage oil spill risks and to monitor them. Governments from across the globe have come up with initiatives to use GIS with remote sensing data for oil spill monitoring [22]. From the Caspian Sea [23] to the Bohai Sea [24], GIS has proved to be essential in studying oil spill distribution, pollution and management. [25] stresses the importance of GIS technology in oil spill monitoring as was reflected in one of the worst oil spills in the world's history, the 2010 Deepwater Horizon oil spill in the Gulf of Mexico. Real time data capture using GIS technology provided an accurate view of the crisis as it unfolded, and identified key infrastructure and natural resources at risk and thus helped decision-making with mobile GIS technology enabling data collection in field and shared amongst responders.

\subsection{Environmental impacts of the MV Wakashio 4.2.1. Characterization of spilled oil}

As [26] state, the type of oil is a key determinant in the severity of the impacts on the different ecosystems and individual species. While heavy oils immediately coat and smother small species, lighter oils can be more toxic in the long term. In addition to this, several other factors like the amount of oil, weathering processes, type of species, oil cleanup strategies amongst others will also determine the impacts [26]. According to the [27], the oil that leaked from the MV Wakashio is a Very Low Sulphur Fuel Oil (VLSFO), an experimental mix of jet fuel and heavy ship oil, whose chemicals have not been publicly divulged. VLSFO is currently described as a 'super-pollutant' by environmental NGOs who have also demanded that it be banned from the Arctic and other parts of the world with environmentally sensitive areas. [28] further assert that as the VLSFO is a new type of oil, the possible long term effects are still unknown.

\subsubsection{Impacts of oil spills on marine waters}

Contamination of marine waters by oil pollution has significant impacts on the physico-chemical properties of the water as well as marine biodiversity. While gas exchange may be reduced in the next few days following the oil spill, weathering processes may result in the breakdown of the oil slick into a thin film (sheen) that may take a long time to dissipate. Emulsification, a process that causes the ocean water to mix with the oil, may also occur due to bad weather conditions such as strong waves thus forming 'chocolate mousse'. Chocolate mousse emulsions cause the oil to sink and disappear from the surface of the water giving the false impression that they are gone when in fact when they can linger in the environment for months to years. As the weather 


\section{International Journal of Engineering Applied Sciences and Technology, 2021 \\ Vol. 6, Issue 4, ISSN No. 2455-2143, Pages 10-19 \\ Published Online August 2021 in IJEAST (http://www.ijeast.com)}

conditions were very harsh during the Wakashio oil spill and subsequent clean-up efforts, it is very probable that chocolate mousse emulsions have formed where the oil has drifted around Mauritius.

Water quality monitoring also has been ongoing at 27 sites of Mauritius from La Cambuse to Trou d'eau Douce since August 07, 2020 for total hydrocarbon and oil and grease with the collaboration of the National Environmental Laboratory, the Albion Fisheries Research Center and the Mauritius Oceanography Institute [29]. Though the components of the oil spilled are unknown, one compound that is usually found in oil, Polycyclic Aromatic Compounds (PAHs), can persist in the environment for years and intoxicate marine and coastal creatures through various routes [30]. According to [31], the level of PAHs decreased in seawater after 7-18 months after the Hebei Spirit oil spill off the west coast of Korea. One of the most ecologically sensitive areas in Mauritius is the Blue Bay Marine Park that [32] fear may face toxic pollution in the long term with ocean circulation. Arsenic levels have also been reported to be 5-7 higher in that region since the oil spill and now petroleum products may deposit on the coral reef in the marine park thus hindering the growth of the reef that has been rejuvenating in the last 20 years [32].

The oil from the Wakashio also reached two river estuaries, Riviere des Creoles and Grand River South East, which are important ecosystems. Oil slicks were found floating above a large and rare area of seagrass meadow where seahorses thrive [28]. Though there was no immediate impact on the seagrass population [28], oil sludge can build up around the plants thereby asphyxiating and poisoning them as well as the marine creatures that live in the meadow.

\subsubsection{Impacts of oil spills on mangrove forests}

[28] declare that as the leak started from the MV Wakashio, ocean currents carried the oil northwards towards the Pointe D'esny mangrove forest, crashing onto the coast of Riviere des Creoles and the surrounding mangroves. [26] state that mangrove forests are highly susceptible to oil pollution, especially those that are located in the tidal zone as the constant ebb and flow of tides constantly bring more oil onto their surface. Oil can either smoother the aerial roots of mangroves and suffocate the root system or cover the leaves and reduce transpiration thus leading to leaf mortality. Additionally, [33] declare that some oil particles may eventually sink to the bottom of the mangrove forests contaminating the sediment which thus further impact on the mangrove biota. As mangroves are important nursery sites for marine creatures, their reproductive capacity can be greatly impaired [31]. By studying the 1992 Era oil spill in southern Australia, [26] concluded that there was no recovery of mangroves for 10 years following the event but seedlings reestablished between 10-25 years later.
4.2.4. Impacts of oil spills on the coast

As of August $11^{\text {th }}, 2020,15 \mathrm{~km}$ of the south-east coast of Mauritius had been affected by the Wakashio oil spill from Pointe Vacoas to Trou d'eau Douce. The oil washed ashore, covered the sandy and rocky beaches at several locations thus enveloping marine creatures that live in those regions such as crabs and barnacles. [31] assert that after the 1989 Exxon Valdez oil spill, the mortality rate in the pink salmon embryos incubating in the intertidal zone of contaminated beaches remained very high for four years. Also, as the oil weathers at sea, tar balls form which can wash ashore. While in the immediacy tar balls can be cleaned up, the constant movement of seawater can cause layers of sand to bury them. [34] report that following the Deepwater Horizon oil spill in April 2010, tar balls several centimeters in thickness were found under sand layers of up to one meter in the northern shores of the Gulf of Mexico while [35] declare that six years after this oil spill, tar balls were still washing on the shore. [36] further contend that tar balls can have significant impacts on wildlife such as physical coating of nesting turtles and birds, exposure to toxic chemicals through ingestion and inhalation of toxic fumes.

\subsubsection{Impacts of oil spills on biodiversity}

[37] assert that oil pollution can severely affect ecosystem biodiversity, eliminate sensitive native species, reduce the reproductive capacity of organisms and make them more susceptible to diseases. [31] report that billions of salmons and herring eggs, 250,000 seabirds, 2800 sea otters, 300 sea otters, 250 bald eagles and up to 22 killer whales died during the Exxon Valdez spill due to oil smothering, drowning, oil ingestion and inhalation and hypothermia. [32] record that one green heron was found oiled and a critically endangered hawksbill turtle was found dead following the Wakashio oil spill. Additionally, thousands of dead marine creatures including eels, sea snakes, Madagascan crabs, octopuses, shell creatures and fish were discovered in between the coast of Le Bouchon to Ilot Broccus [38]. Since seabirds nest on the offshore islets where the spill occurred, they could be affected over the years through oil ingestion or inhalation. Additionally, as the oil enveloped Ile aux Aigrettes, it is possible that it may have infiltrated its delicate ecosystem [28], accumulating in native plants, birds and reptiles thus leading to their eventual poisoning in the long term [32]. Moreover, 39 dead dolphins and melon-headed whales washed ashore the south-east coast following the Wakashio oil spill that [38] contend had thin films of oil around the blowholes and skins while official records claim that there was no trace of hydrocarbons on the mammals [39].

As for coral reefs, [40] declare that these organisms require clear waters to grow and the slick may impact on light penetration thus preventing their growth. Also, as the oil particles sink to the bottom, they can kill zooplankton that are found on the reefs and weaken the ability of corals to photosynthesize. As it is, [38] reports that the spawning of 


\section{International Journal of Engineering Applied Sciences and Technology, 2021 \\ Vol. 6, Issue 4, ISSN No. 2455-2143, Pages 10-19 \\ Published Online August 2021 in IJEAST (http://www.ijeast.com)}

corals in late October to early November in the south-east of Mauritius was greatly affected by the oil spill raising questions on the toxicity of the oil. [28] further declares that as the weather conditions were very harsh during the wreck of the MV Wakashio, the ship was pushed against the coral reef damaging it and causing heaps of sand to fill the crevice. This led to the formation of a sand bar inside the reef which may change the water currents in the lagoon and impact on coral growth [28]. To be sure, years after an oil spill, the live coral extent may decrease but as coral reefs are resistant species, they can recover to pre-spill levels as [41] demonstrate after the Caribbean Panama oil spill of 1986.

Additionally, [37] declare that fish and invertebrates can biomagnify certain chemicals to million times higher than what is found in the natural environment thereby affecting the coastal and marine food webs up to human consumption. Though there have been very few attempts to understand the impacts of oil spills on marine food webs, [42] studied the Deepwater Horizon oil spill to create a framework to assess such impacts that can also be used to make future predictions.

\section{CONCLUSION}

Marine oil spills are one of the most menacing environmental concerns around the world today as they can have immediate disastrous effects to unfathomable long-term consequences. The recent oil spill of the MV Wakashio into the coastal waters of Mauritius demonstrates the need for concrete strategies to detect and monitor oil spills and strengthen pollution preparedness. Thus, this study used a GIS based approach to assess the environmental impacts of the MV Wakashio oil spill in the south eastern region of Mauritius and demonstrate its usefulness in monitoring marine oil spills. Satellite images were retrieved from the Copernicus platform and processed using ArcGIS to map the extent of the oil spill; GPS coordinates from ground truth were recorded and a map of the affected sites was created to survey the existing type of environment and biodiversity. From this data, the short and long term environmental impacts of the Wakashio oil spill were assessed, though there has been limited research on the particular VLSFO that was spilled. GIS has proved to be an excellent tool to support management and decision making regarding oil spill preparedness and monitoring especially for a SIDS like Mauritius. With rapid population growth and an on-going dependency on fossil fuels like oil, transportation of such materials across the world's oceans poses an enormous risk to the marine and coastal ecosystems. Thus, to meet these new challenges, oil spill response plans need to be upgraded and models that describe the impacts of such spills must be incorporated.

\section{Acknowledgements}

The authors are grateful to Mr Lildaree S.J.C. for helping to process the satellite images and Mr Oh-Seng J.R. from the
Ministry of Environment, Solid Waste Management and Climate Change of Mauritius for the valuable insight he brought to this paper.

\section{REFERENCE}

1. Fustes, D., Cantorna, D., Dafonte, C., Arcay, B., Iglesias, A. and Manteiga, M. (2014). A cloudintegrated web platform for marine monitoring using GIS and remote sensing. Application to oil spill detection through SAR images. Future Generation Computer Systems, vol. 34, (pp. 155-160).

2. Kulawiak, M., Prospathopoulos, A., Perivoliotis, L., Kioroglou, S. and Stepnowski, A. (2010). Interactive visualization of marine pollution monitoring and forecasting data via a Web-based GIS. Computers \& Geoscience, vol. 36, no.8, (pp. 1069-1080).

3. Fan, J., Zhang, F., Zhao, D. and Wang, J. (2015). Oil spill monitoring based on SAR remote sensing imagery. Aquatic Procedia, vol. 3, (pp. 112-118).

4. Neumann, B., Vafeidis, A.T., Zimmermann, J. and Nicholls, R.J. (2015). Future coastal population growth and exposure to sea-level rise and coastal flooding A global assessment. PLoS One, vol. 10, (pp. 1-34).

5. Kato, N., Choyekh, M., Dewantara, R., Senga, H., Chiba, H., Kobayashi, E., Yoshie, M., Tanaka, T. and Short, T. (2017). An autonomous underwater robot for tracking and monitoring of subsea plumes after oil spills and gas leaks from seafloor. Journal of Loss Prevention in the Process Industries, vol. 50, (pp. 386-396).

6. Petzold, J. and Magnan, A.K. (2019). Climate change: thinking small islands beyond Small Island Developing States (SIDS). Climatic Change, vol. 152, (pp. 145-165).

7. UN-OHRLLS. (2020). State of the least developed countries. Retrieved October 18, 2020, from https://unohrlls.org/custom-

content/uploads/2017/07/State-of-theLDCs_2017.pdf

8. Daniel, A. (2020). From Beirut to Mauritius. Windward. Retrieved January 03, 2020, from https://www.wnwd.com/insights/from-beirut-tomauritius/

9. Bueger, C. (2020). Mauritius oil spill: was the government unprepared? The African Report. Retrieved December 21, 2020, from https://www.theafricareport.com/38866/mauritiusoil-spill-was-the-government-unprepared/

10. Krestenitis, M., Orfanidis, G., Ioannidis, K., Avgerinakis, K., Vrochidis, S. and Kompatsiaris, I. (2019). Oil spill identification from satellite images 


\section{International Journal of Engineering Applied Sciences and Technology, 2021 \\ Vol. 6, Issue 4, ISSN No. 2455-2143, Pages 10-19 \\ Published Online August 2021 in IJEAST (http://www.ijeast.com)}

using deep neural networks. Remote Sensing, vol. 11, no. 15, (pp. 1762).

11. Government of Mauritius. (2020). Restricted Areas in the south east region. Retrieved December 12, 2020, from

https://environment.govmu.org/Documents/wakashio /Restricted\%20Areas\%20in\%20the\%20SE\%20Regio n.pdf

12. Saddul, P. (2002). A Geomorphological Analysis. Moka, Mauritius: MGI, (262-267 pp.).

13. Yonature. (2020). Coastal and marine biodiversity of Mauritius. Retrieved October 31, 2020, from https://www.yonature.com/coastal-marinebiodiversity-mauritius/

14. Reyne, M., Webster, I. and Huggins, A. (2017). A preliminary study on the sea turtle density in Mauritius. Marine Turtle Newsletter, vol. 152, (pp. 58).

15. Webster, I., Cockcroft, V., Cadinouche, A. and Huggins, A. (2020). Cetacean diversity of Mauritius. Journal of Cetacean Research Management, vol. 21, (pp. 45-58).

16. Nelson, J.R. and Grubesic, T.H. (2019). Oil spill modeling: computational tools, analytical frameworks, and emerging technologies. Progress in Physical Geography, vol. 43, (pp. 129-143).

17. Government of Mauritius. (2020). MV Wakashio:Daily progress reports submitted by salvage master says, Minister Maudhoo. Retrieved December 12, 2020, from http://www.govmu.org/English/News/Pages/MVWakashio-Daily-progress-reports-submitted-bysalvage-master-says-Minister-Maudhoo.aspx

18. Samy, S. (2020). Post-MV Wakashio: 56 projets soumis au Mauritius Research and Innovation Council. Retrieved November 19, 2020, from https://www.inside.news/post-mv-wakashio-56projets-soumis-au-mauritius-research-andinnovation-council/

19. Hook, S., Batley, G., Holloway, M., Ross, A. and Irving, P. (2016). Oil Spill Monitoring Handbook. Clayton, Australia: Csiro Publishing, (266 pp.).

20. Ivanov, A.Y. and Zatyagalova, V. (2008). A GIS approach to mapping oil spills in a marine environment. International Journal of Remote Sensing, vol. 29, no. 21, (pp. 6297-6313).

21. Ivanov, A.Y. and Ermoshkin, I.S. (2004). Mapping oil spills in the Caspian sea using ERS-1/ERS-2 SAR image quick-looks and GIS. Gayana (Concepción), vol. 68, no. 2, (pp. 297-304).

22. Kesava, R.P., Kishore, K.J., Kumar, L.J.V. and Murthy, R. (2016). RS - GIS based Operational Monitoring of Indian Maritime and Environs. IJEE, vol. 9, no.3, (pp. 84-92).
23. Pashayev, N.M., Ragimov, R.M., Samedov, F.R. and Gahramanova, D.S. (2018). Aerospace monitoring of the oil pollution of the Caspian Sea on the base of GIS technology and radar space images. IFACPapersOnLine, vol. 51, no. 20, (pp. 558-560).

24. Bing, L., Xing, Q.G., Liu, X. and Zou, N.N. (2019). Spatial distribution characteristics of oil spills in the Bohai Sea based on satellite remote sensing and GIS. Journal of Coastal Research, vol. 90, (pp. 164-170).

25. Johnson, R. (2017). Cleaning up the Deepwater Horizon oil spill using GIS. Esri Australia. Retrieved January 05, 2021, from https://esriaustralia.com.au/blog/cleaning-deepwaterhorizon-oil-spill-using-gis

26. Connolly, R.M., Connolly, F.N. and Hayes, M.A. (2020). Oil spill from the Era: Mangroves taking eons to recover. Marine Pollution Bulletin, vol. 153, (pp. 110965).

27. IMO. (2020). Responding to MV Wakashio oil spill. Retrieved January 05, 2021, from https://www.imo.org/en/MediaCentre/HotTopics/Pag es/Wakashio-FAQ.aspx

28. Sauzier, J. (2020). How Mauritius is cleaning up after major oil spill in biodiversity hotspot, Nature. Retrieved October 21, 2020, from https://www.nature.com/articles/d41586-020-024467

29. Government of Mauritius. (2020). MV Wakashio: Environmental monitoring of terrestrial and marine resources. Retrieved January 05, 2020, from http://www.govmu.org/English/News/Pages/Environ mental-monitoring-of-terrestrial-and-marineresources.aspx

30. Abdel-Shafy, H.I. and Mansour, M.S. (2016). A review on polycyclic aromatic hydrocarbons: source, environmental impact, effect on human health and remediation. Egyptian Journal of Petroleum, vol. 25, no.2, (pp. 107-123).

31. Barron, M.G., Vivian, D.N., Heintz, R.A. and Yim, U.H. (2020). Long-Term Ecological Impacts from Oil Spills: Comparison of Exxon Valdez, Hebei Spirit, and Deepwater Horizon. Environmental Science and Technology, vol. 54, (pp. 6456-6467).

32. Pasnin, O., Sunassee, S., Tatayah, V., Turner, A. and Ward C. (2020). What will be the environmental impact of the Mauritius oil spill? Africa Arguments. Retrieved January 04, 2020, from https://africanarguments.org/2020/09/what-will-bethe-environmental-impact-of-the-mauritius-oil-spill/

33. Onyena, A.P. and Sam, K. (2020). A review of the threat of oil exploitation to mangrove ecosystem: Insights from Niger Delta, Nigeria. Global Ecology and Conservation, vol. 22, (pp. e00961).

34. Beyer, J., Trannum, H.C., Bakke, T., Hodson, P.V. and Collier, T.K. (2016). Environmental effects of 


\section{International Journal of Engineering Applied Sciences and Technology, 2021 \\ Vol. 6, Issue 4, ISSN No. 2455-2143, Pages 10-19 \\ Published Online August 2021 in IJEAST (http://www.ijeast.com)}

the Deepwater Horizon oil spill: a review. Marine Pollution Bulletin, vol. 110, no. 1, (pp.28-51).

35. Pitts, S. (2016). 6 years after BP oil spill, tar balls continue to wash onto AL beaches. WSFA12. Retrieved January 04, 2020, from https://www.wsfa.com/story/31957281/6-years-afterbp-oil-spill-tar-balls-continue-to-wash-onto-albeaches/

36. Warnock, A.M., Hagen, S.C. and Passeri, D.L. (2015). Marine tar residues: a review. Water, Air, \& Soil Pollution, vol. 226, no. 3, (pp.68).

37. Kibria, G., Hossain, M.M., Mallick, D., Lau, T.C. and $\mathrm{Wu}, \mathrm{R}$. (2016). Trace/heavy metal pollution monitoring in estuary and coastal area of Bay of Bengal, Bangladesh and implicated impacts. Marine Pollution Bulletin, vol. 105, no. 1, (pp.393-402).

38. Degnarain, N. (2020). Island Of Death: Thousands Of Sea Creatures Found Dead Five Miles From Wakashio Wreck, Forbes. Retrieved January 03, 2020, from https://www.forbes.com/sites/nishandegnarain/2020/ $\underline{10 / 09 / \text { island-of-death-thousands-of-sea-creatures- }}$ found-dead-5-miles-from-wakashiowreck/?sh=42f554e92099

39. Paravicini, G. and Houreld, K. (2020). 'Heartwrenching': at least 40 dolphins dead near Mauritius oil spill, Reuters. Retrieved December 28, 2020, from https://www.reuters.com/article/ukmauritius-environment-dolphins/heartwrenching-atleast-40-dolphins-dead-near-mauritius-oil-spillidUKKBN25O1KM?edition-redirect=uk

40. Pilly, S.S., Turner, J., and Roche, R., 2020. Mauritius oil spill: how coral reefs, mangroves and seagrass could be affected, The Conversation. Retrieved January $\quad 04, \quad 2020, \quad$ from https://theconversation.com/mauritius-oil-spill-howcoral-reefs-mangroves-and-seagrass-could-beaffected-144954

41. Guzman, H.M., Kaiser, S. and Weil, E. (2020). Assessing the long-term effects of a catastrophic oil spill on subtidal coral reef communities off the Caribbean coast of Panama (1985-2017). Marine Biodiversity, vol. 50, (pp. 1-19).

42. McCann, M.J., Able, K.W., Christian, R.R., Fodrie, F.J., Jensen, O.P., Johnson, J.J., López-Duarte, P.C., Martin, C.W., Olin, J.A., Polito, M.J. and Roberts, B.J. (2017). Key taxa in food web responses to stressors: the Deepwater Horizon oil spill. Frontiers in Ecology and the Environment, vol. 15, no. 3, (pp. 142-149). 